J. Vision. 4(9), 711-20 (2004). Retrieved from http:// ww.journalofvision.org/content/4/9/4.full

61. Olkkonen, M., Brainard, D.H.: Perceived glossiness and lightness under real-world illumination. J. Vis. 10(9), 5 (2010). doi10.1167/10.9.5

62. Olkkonen, M., Brainard, D.H.: Joint effects of illumination geometry and object shape in the perception of surface reflectance. Iperception 2(9), 1014-1034 (2011). doi:10.1068/i0480

63. Olkkonen, M., Hansen, T., Gegenfurtner, K.R.: Color appearance of familiar objects: effects of object shape, texture, and illumination changes. J. Vis. 8(5) (2008). Retrieved from http://www.journalofvision.orgwww. journalofvision.org/content/8/5/13.full

64. Poirson, A.B.., Wandell, B.A.: Appearance of colored patterns: pattern-color separability. J. Opt. Soc. Am. A. 10(12), 2458-2470 (1993). Retrieved from http://white.stanford.edu/ brian/papers/color/ smatch.pdf

65. Radonjić, A., Todorović, D., Gilchrist, A.: Adjacency and surroundedness in the depth effect on lightness. J. Vis. 10(9) (2010). Retrieved from http://171.67.113. 220/content/10/9/12.full

66. Ripamonti, C., Bloj, M., Hauck, R., Mitha, K., Greenwald, S., Maloney, S.I., Brainard, D.H.: Measurements of the effect of surface slant on perceived lightness. J. Vis. 4(9) (2004). Retrieved from http://www. journalofvision.orgwww.journalofvision.org/content/4/ 9/7.full

67. Robilotto, R., Zaidi, Q.: Limits of lightness identification for real objects under natural viewing conditions. J. Vis. 4(9) (2004). Retrieved from http://ww.w. journalofvision.org/content/4/9/9.full

68. Rosenberg, C., Ladsariya, A., Minka, T.: Bayesian color constancy with non-Gaussian models. In: Advances in Neural Information Processing Systems (2003)

69. Shevell, S.K.: The dual role of chromatic backgrounds in color perception. Vision Res. 18(12), 1649-1661 (1978). Retrieved from http://deepblue.lib.umich.edu/ bitstream/2027.42/22782/1/0000337.pdf

70. Shi, L., Funt, B. V.: Re-processed version of the Gehler color constancy database of 568 images. Simon Fraser University (2010)

71. Smet, K., Ryckaert, W.R., Pointer, M.R., Deconinck, G., Hanselaer, P.: Colour appearance rating of familiar real objects. Color Res. Appl. 36(3), 192-200 (2011). Retrieved from http://www.esat.kuleuven.be/electa/ publications/fulltexts/pub_2070.pdf

72. Smithson, H.E.: Sensory, computational and cognitive components of human colour constancy. Philos. Trans. R. Soc. Lond. B Biol. Sci. 360(1458), 1329-1346 (2005). doi:10.1098/rstb.2005.1633

73. Troost, J.M., De Weert, C.M.M.: Naming versus matching in color constancy. Percept. Psychophys. 50(6), 591-602 (1991). Retrieved from http://link. springer.com/article/10.3758/BF03207545

74. Van De Weijer, J., Gevers, T., Gijsenij, A.: Edge-based color constancy. IEEE Trans. Image Process. 16(9),
2207-2214 (2007). Retrieved from http://hal.archivesouvertes.fr/docs/00/54/86/86/PDF/IP07_vandeweijer.pdf

75. Van De Weijer, J., Schmid, C., Verbeek, J.: Using high-level visual information for color constancy. In: Computer Vision, 2007. ICCV 2007. IEEE 11th International Conference on. IEEE (2007)

76. von Kries, J.: Chromatic adaptation. Festschrift der Albrecht-Ludwigs-Universität, pp. 145-158. (1902)

77. Walraven, J.: Discounting the background - the missing link in the explanation of chromatic induction. Vision Res. 16(3), 289-295 (1976). Retrieved from http:// www.sciencedirect.com/science/article/pii/004269897 6901127

78. Webster, M.A., Mollon, J.D.: Colour constancy influenced by contrast adaptation. Nature 373(6516), 694-698 (1995). Retrieved from http://www.nature. com/nature/journal/v373/n6516/abs/373694a0.html

79. Werner, A.: Color constancy improves, when an object moves: high-level motion influences color perception. J. Vis. 7(14) (2007). Retrieved from http://wwww. journalofvision.org/content/7/14/19.full

80. Xiao, B., Hurst, B., MacIntyre, L., Brainard, D.H.: The color constancy of three-dimensional objects. J. Vis. 12(4), 6 (2012). doi:10.1167/12.4.6

81. Zaidi, Q., Bostic, M.: Color strategies for object identification. Vision Res. 48(26), 2673-2681 (2008). doi:10.1016/j.visres.2008.06.026

\section{Color Contrast}

Lois Swirnoff $^{1}$, Nilgün Olguntürk ${ }^{2}$ and Gertrud Olsson ${ }^{3}$

${ }^{1}$ The Cooper Union for the Advancement of

Science and Art Cooper Square, New York, NY, USA

${ }^{2}$ Department of Interior Architecture and Environmental Design, Faculty of Art, Design and Architecture, Bilkent University, Ankara, Turkey

${ }^{3}$ School of Architecture, KTH, Royal Institute of Technology, Stockholm, Sweden

\section{Synonyms}

Chromatic contrast

\section{Definition}

Color contrast describes the perceptual effects of colors' adjacency in contexts, whether they occur 
and are observed in two- or three-dimensional space. It is the relationship between the color of a stimulus and that of its immediate surround.

\section{Overview}

The concept of color contrast is concerned with the perception of color itself and is based upon the idea that the eye - the visual system - evaluates, a function of thinking. Light and color are therefore not merely surface phenomena but are intrinsic to human vision, to sight and insight. Light and color contrasts are primary attributes of vision. They signal the reactive eye to initiate and activate the complex visual system to respond to the visual world.

Fundamentally, the perceptions of the visual world, in its enormous diversity - the environment, man made or natural; people; places; animals; and vegetal life-space itself - are distinguished and contextualized by the glorious capacity to see. The primary function of the visual system evolved to react to this diversity of features as complex contrasts of shapes and colors. These formal attributes originate and are embodied in the response of the human eye to gradients of light and its absence, shadow. Gibson links the concept of gradient to both formal and spatial effects, as well as other incremental changes [1]. In the context of color contrast, it is possible to use this concept to express increments of light and color. It is possible to think of this as a "quantification without number." Color originates in the environment and in the visual system, as a complex and selective response to light.

Visual artists, as abstract or figurative painters, are experts in defining the images they create on two-dimensional surfaces by analyzing and expressing them as shapes and areas of light and color. All visual languages require this ability. Figurative painting depends upon the narrative orchestration of these components; for abstract works of art, shapes and colors, with their strong associative attributes, suffice as expressive forms. Now, how does the visual system make sense in the first place of the complexity of the visual world? By responding to its gradients of light and colors as areas of contrast (Fig. 1).

But color, as Josef Albers asserted, is the most changeable component in art. And the painter Delacroix boasted he could turn a mud color into gold. It is all a matter of context. Chevreul, the chemist, in the nineteenth century defined "simultaneous contrast" as the influence of colors in backgrounds to affect the appearance of colors within their boundaries [2]. Thus, for example, a middle gray against a black background looks light, while that same gray against a light background appears dark. Lights and darks are particularly susceptible to change (Figs. 2 and 3).

Josef Albers, in the twentieth century, explored and exhaustively expanded the simultaneous contrast law, as well as the Bezold effect, the Liebmann effect, Fechner's psychophysical laws, and Goethe's perceptual concepts, by his and his

\section{Color Contrast,}

Fig. 1 Lois Swirnoff: Santa Fe Rhythm, acrylic on folded paper

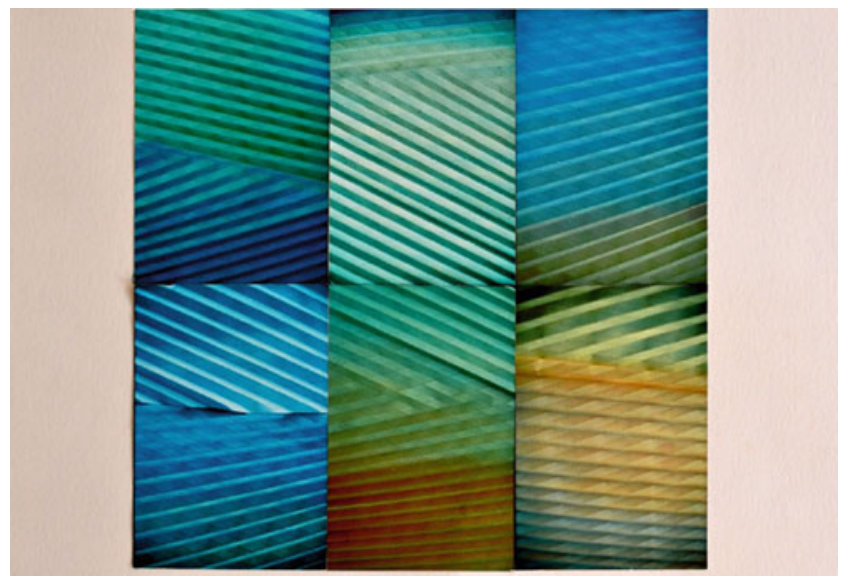




\section{Color Contrast,}

Fig. 2 The same gray appears as two

Color Contrast,

Fig. 3 Scales of gray
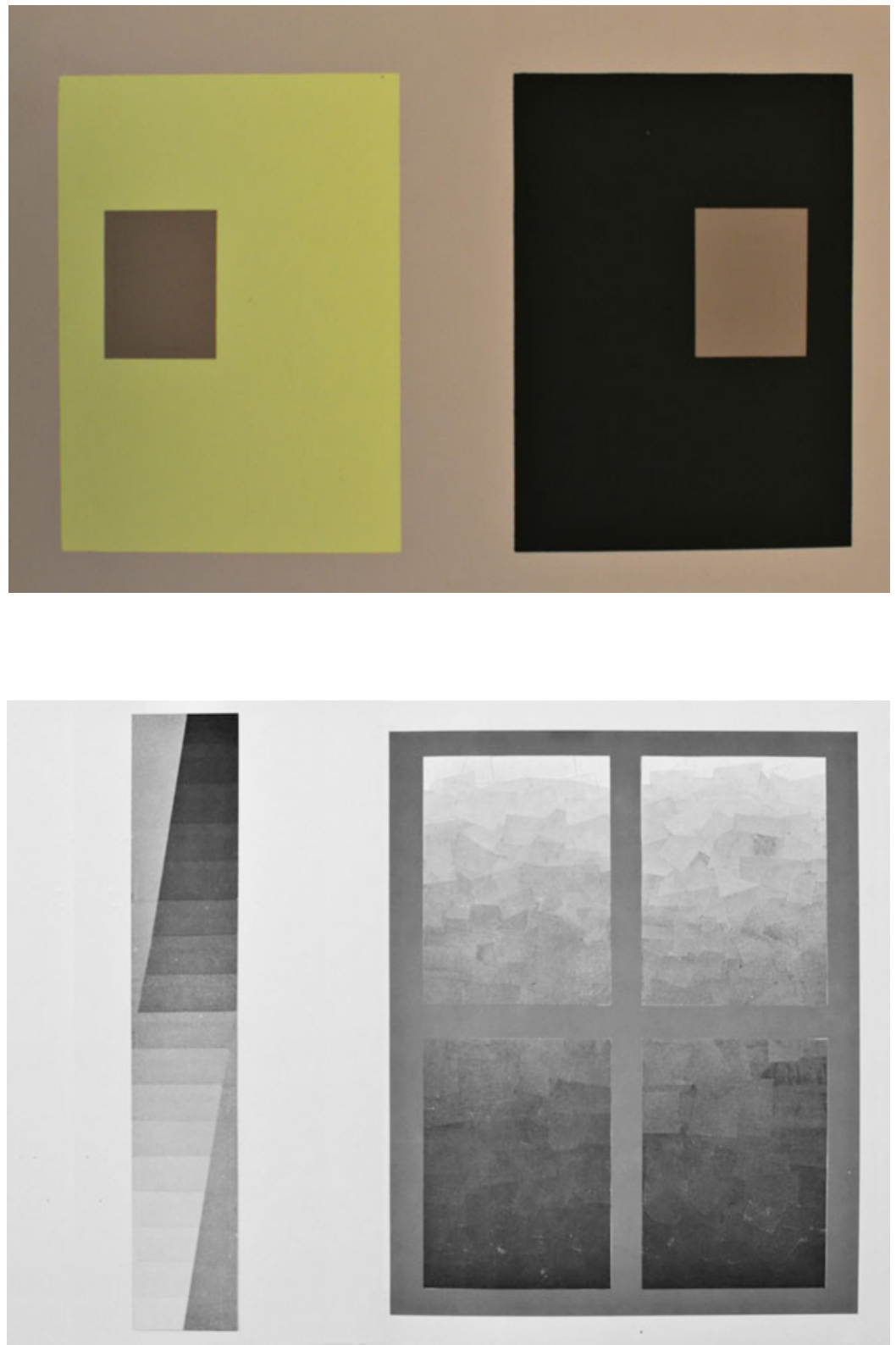

students' experiments and in his great work, The Interaction of Color [3]. In it, the empirical studies which entailed figure/ground relationships were explored far beyond Chevreul's. To the extent that contrasts between color complements, like a yellow and a violet, against opposing backgrounds, could appear to be similar (Figs. 4, 5, 6, and 7).
Underlying Albers' discoveries is the function of the visual system - the afterimage. The stimulus of a bright red area, after 30-60 seconds of exposure to the eye, will appear bright green. Just as staring at the bright light of a window in a darkened room appears as a dark window, when the eyes are diverted or shut. Another was the contrast boundary, the thin line at the edge of a 
color figure which appears against a contrasting background, initiating the reaction of a color change. Application of gradients of colors as linear planes can cause mixtures between adjacent

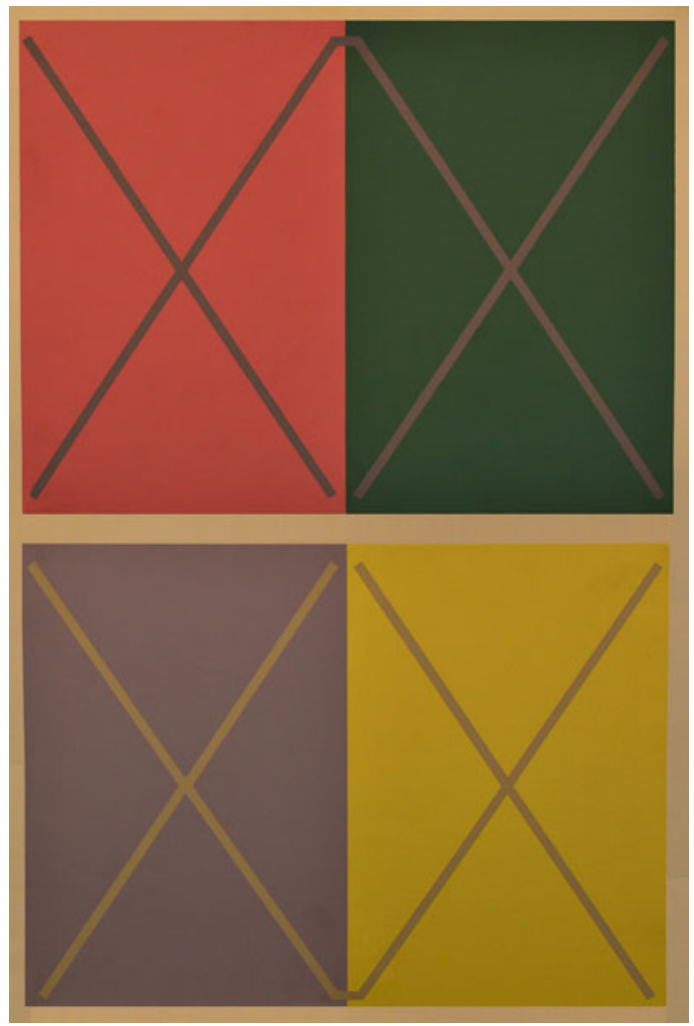

Color Contrast, Fig. 4 Reverse ground: each $\mathrm{X}$ is the same color color boundaries to appear as an additive third, i.e., a combined effect which regenerates the appearance of light. Changing the quantity of this gradient between two colors in a painting can cause many additive mixtures to be created. The work of Julian Stanczak and Richard Anuskiewicz, former graduate students of Albers, explore these phenomena and created the movement of Op Art in the 1960s in the United States (Fig. 8). The researchers Leo Hurvich and Dorothea Jameson describe this phenomenon in their article "From contrast to assimilation; in art and in the eye" [4] and attribute it to an opponent response system in human vision, beginning at the retina. They are proponents of the theories of Ewald Hering, whose book Outlines of a Theory of the Light Sense they translated into English [5].

Swirnoff's experimental work with color began with a question: What happens to color interactions lifted from the two-dimensional plane when they interact in space? Will contrast boundaries prevail in adjacent colors when they appear as sequences of planes in space, as they do on the 2-D surface? Do the size and/or placement of volumes appear different when their surfaces reflect contrasting hues? How are clues to size and distance influenced by color? What is the influence of reds (long wavelength) to blues (short wavelengths) on the appearance of volumes in space?

Beginning with Gestalt principles of form and organization, size and placement, proximity,

\section{Color Contrast,}

Fig. 5 Reverse

ground: disc

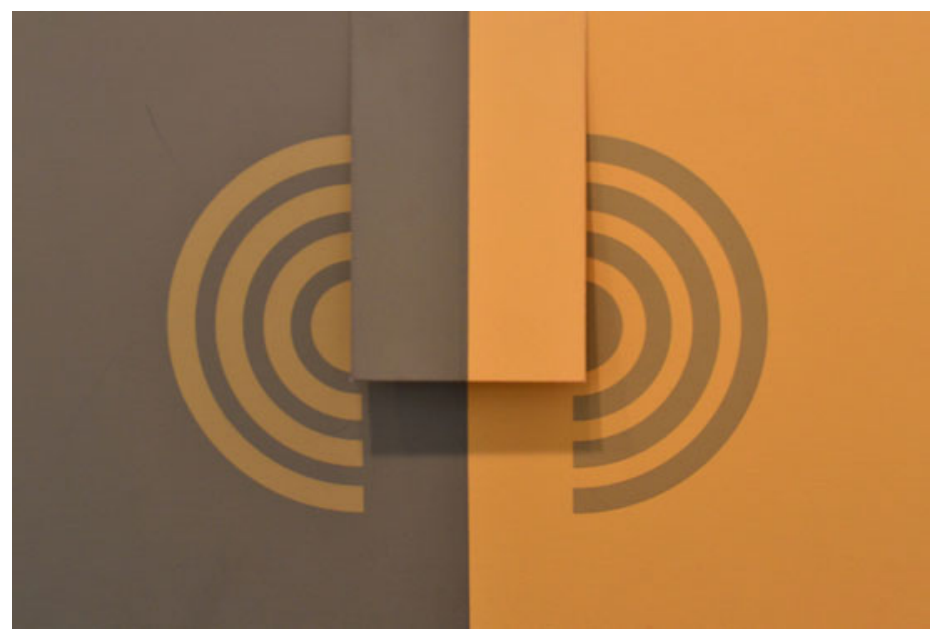




\section{Color Contrast,}

Fig. 6 Three colors appear as two

\section{Color Contrast,}

Fig. 7 Complementary colors violet and yellow appear equal
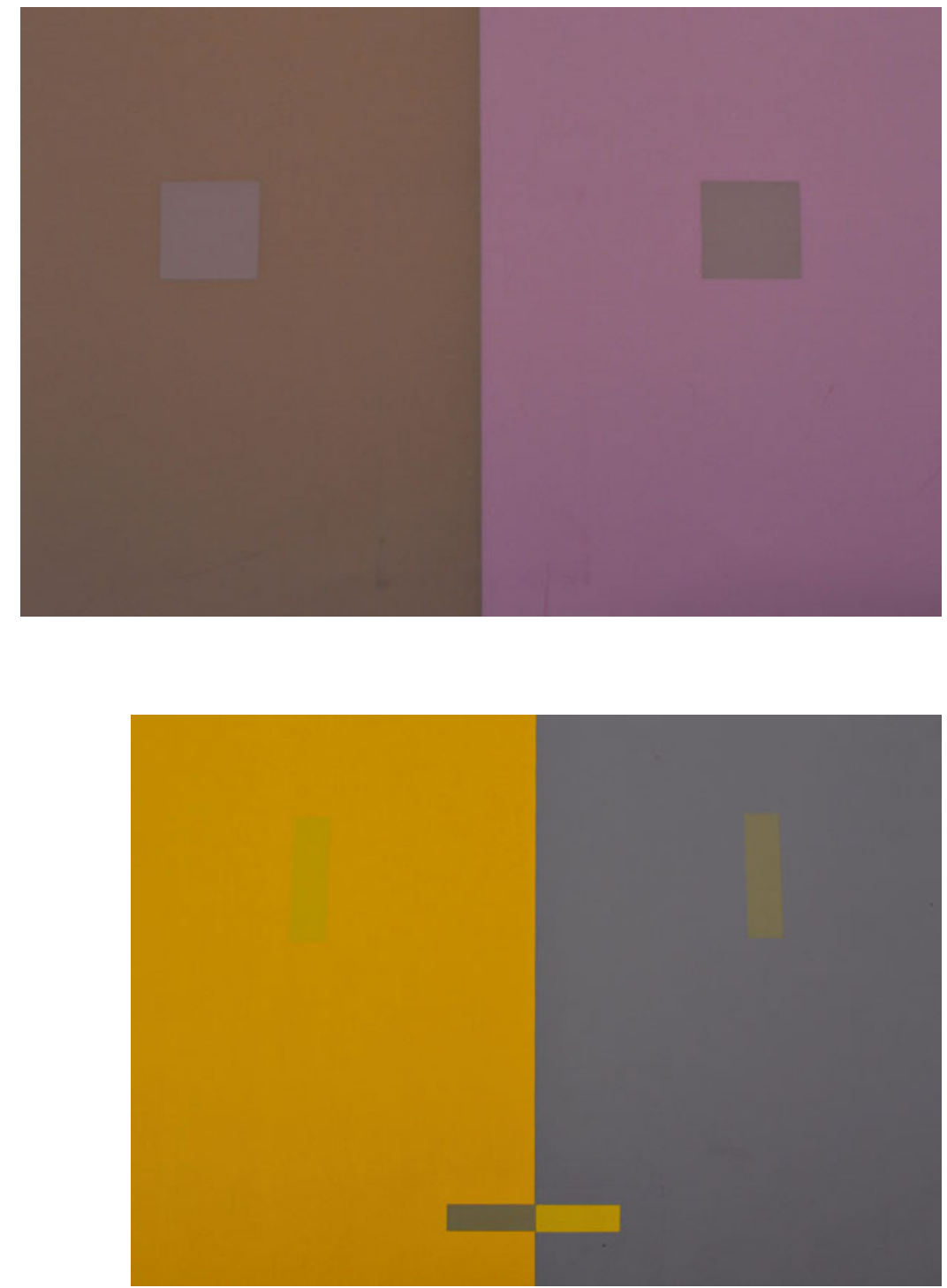

clustering, and grouping, Swirnoff applied primary surface colors (Color-Aid) to cubes or floating planes, differing in size and placement in a space frame, and observed their effects through a series of experiments. These findings are the subject of the paper titled "Spatial Aspects of Color," a thesis written for her Master of Fine Arts at Yale University in 1956.

Since then, Swirnoff's experiments with her students of design, over more than three decades, have explored contrast effects spatially, from tabletop experiments to collaborations of environmental scale, published in her book Dimensional
Color [6]. These experiments have resulted in the assertion that color can be defined as a nonlinear dimension.

A new phenomenon was discovered: color stereopsis (Figs. 9, 10, 11, 12, 13, and 14). This occurs when three interrelated colors, separated sequentially in a space/frame, are observed frontally through a square opening. In this study, the contrast boundary between an intermediary color, seen as adjacent to two, one placed behind, the other in front, disappears. With the absence of the middle intermediary, the visual system prefers to see the two color planes, which are frontally 


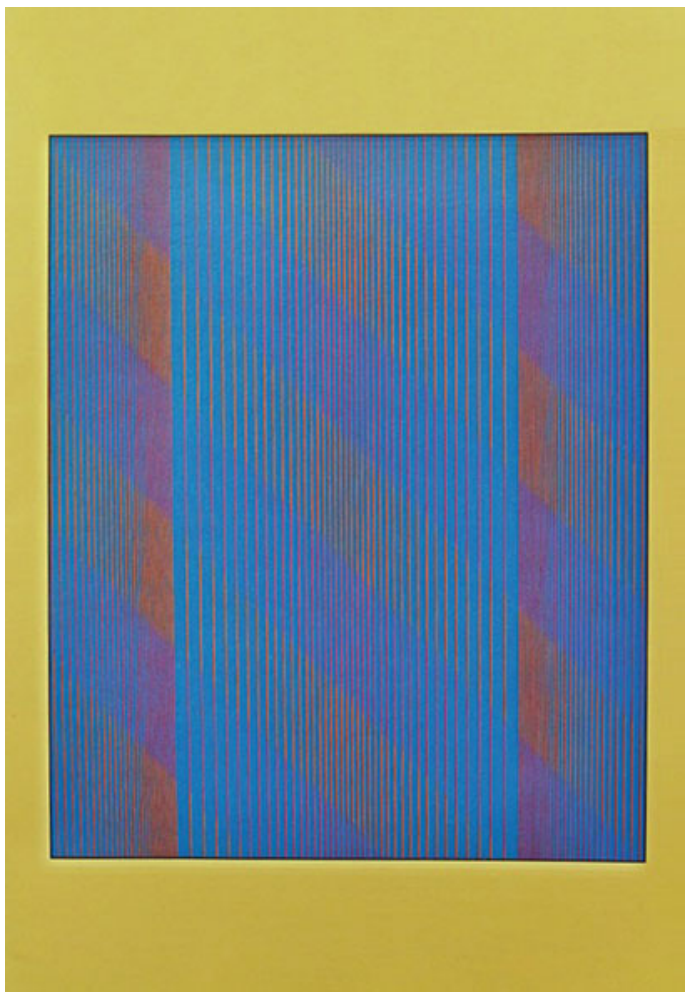

Color Contrast, Fig. 8 Julian Stanczak: Blue Squeeze, acrylic on canvas

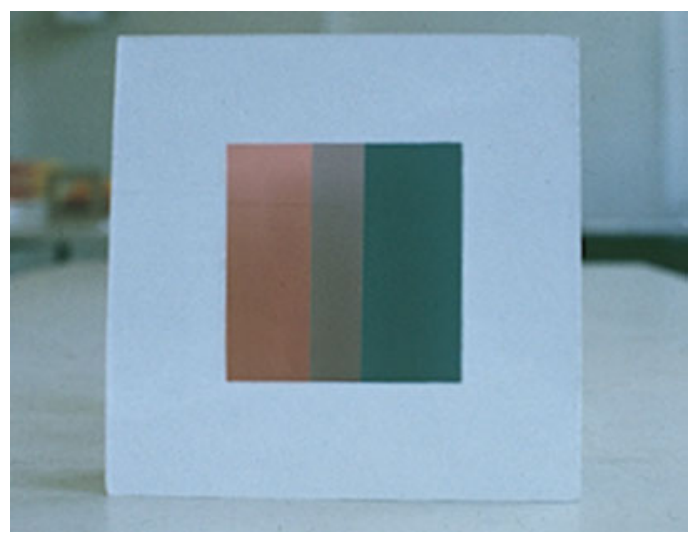

Color Contrast, Fig. 9 Color stereopsis: three colors fuse as two, red/green

aligned in the space frame, appear to rotate to a diagonal position, and as they appear to intersect, trigger a strong stereoptic effect, analogous to the experience of depth when two flat images of the same subject, seen through a "stereopticon" - differing slightly in their position - fuse.

In a problem devised to test the degree of light and shadow that defines a square pyramid, models were placed against the walls of the teaching studio to observe the patterns of light and shadow which reflect from the four white triangles of its faces (Figs. 15 and 16). The challenge - to see what degrees of contrast produced the visual effect of a pyramid - entailed placing gray papers ranging from white to black against the model in reversed order, to cancel the pattern of light and dark, causing it to appear flat, without altitude. It was found that the degree of change in the contrast values perceived, with scales of gray papers, between white to black was geometric - far greater than anticipated. Once found, the contrasting grays, applied to the four triangles in opposed order to their original appearance, matched. The contrast boundaries disappeared, and the model took the appearance of a flattened surface, a bisected figure or a pyramid of increased altitude, when rotated against the wall or in the hand. Thus, the response of the visual system to contrasts of light and dark depends upon ratios rather than measurable reflectances.

With a grant from the IIDA, Swirnoff was able to conduct a room-sized experiment, with students in the lighting studio of Parson's School of Design in New York. The issue was to test the effect of colored light, projected on interior surfaces. The room's interior was constructed of four nine-foot squares, three comprised the walls - two lateral ones were connected by $90^{\circ}$ to the third back wall - all three joined to the fourth square as the floor, an open cube. Using theatrical gels, colored light was projected onto these surfaces, and it was observed how they affected the spatial appearance of the room (Figs. 17 and 18).

Color generated by light greatly intensifies and enhances the experience of color contrasts. Both ends of the visual spectrum were tried (long wave, reds and yellows, then short wave, blues) sequentially, in separate experiments, and the differences in spatial experience by the contrasts each presented, as anticipated, were obvious. The "red room," however, provided more phenomena [6]. 


\section{Color Contrast,}

Fig. 10 Diagram: their spatial appearance

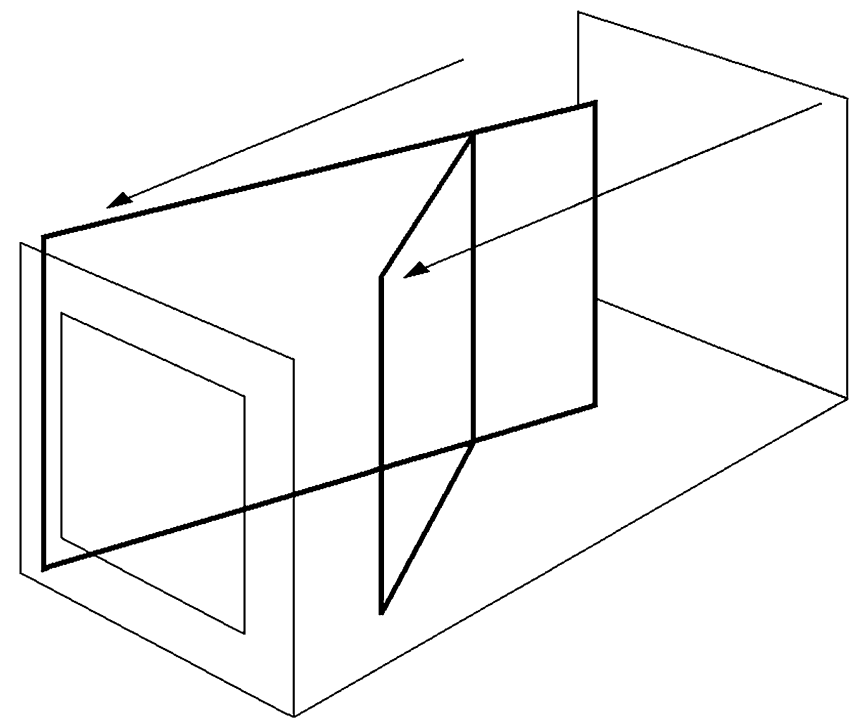

\section{Color Contrast,}

Fig. 11 Diagram: spatial placement of three planes

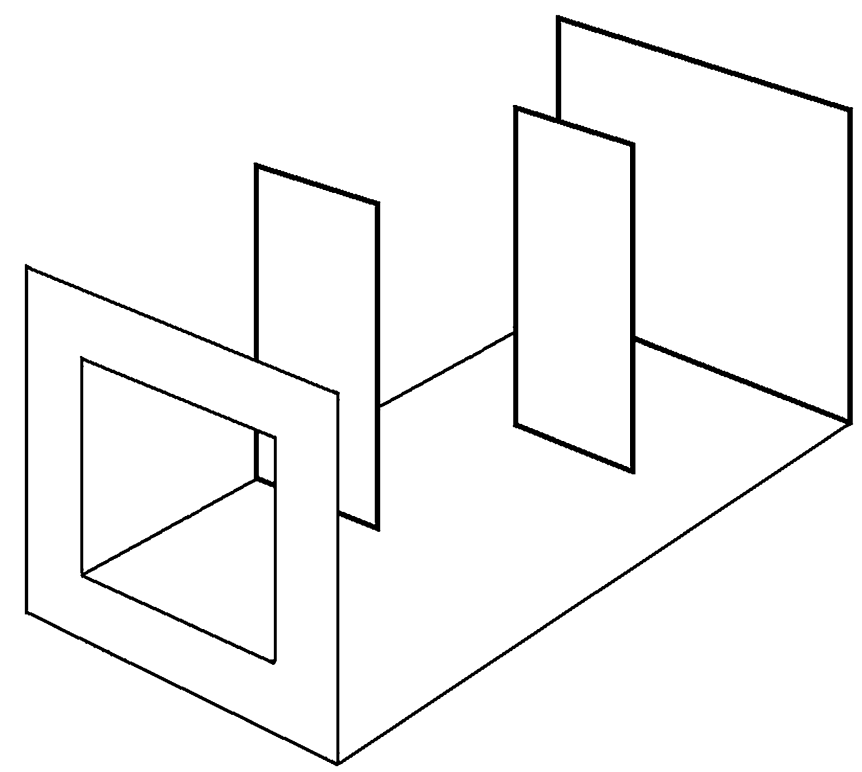

Against the back wall adjacent to the lateral wall planes, illuminated with red, a neutralized yellow light was projected, to fill its square surface. At the $90^{\circ}$ juncture color contrasts intensified; when observed over time, a neutralized yellow light was seen, reflected from the back wall, adjacent to the red lateral wall, change at their mutual boundaries, at first to a green edge and then followed by the green filling in the entire square! While the adjacent red wall increasingly appeared warmer, and at the contrast boundary, the $90^{\circ}$ juncture with the green began to reflect a yellowish light.

These changes were observed as they occurred over a period of about $8-10 \mathrm{~min}$, when surprisingly, the green at its contrast boundary with the yellowing red changed to blue/violet.

There had been a complete change in the colors of the contrast boundaries, beginning originally as a yellow-projected light, which changed the entire 


\section{Color Contrast,}

Fig. 12 Color stereopsis

value sequence of three reds

\section{Color Contrast,}

Fig. 13 Diagram: their

spatial appearance
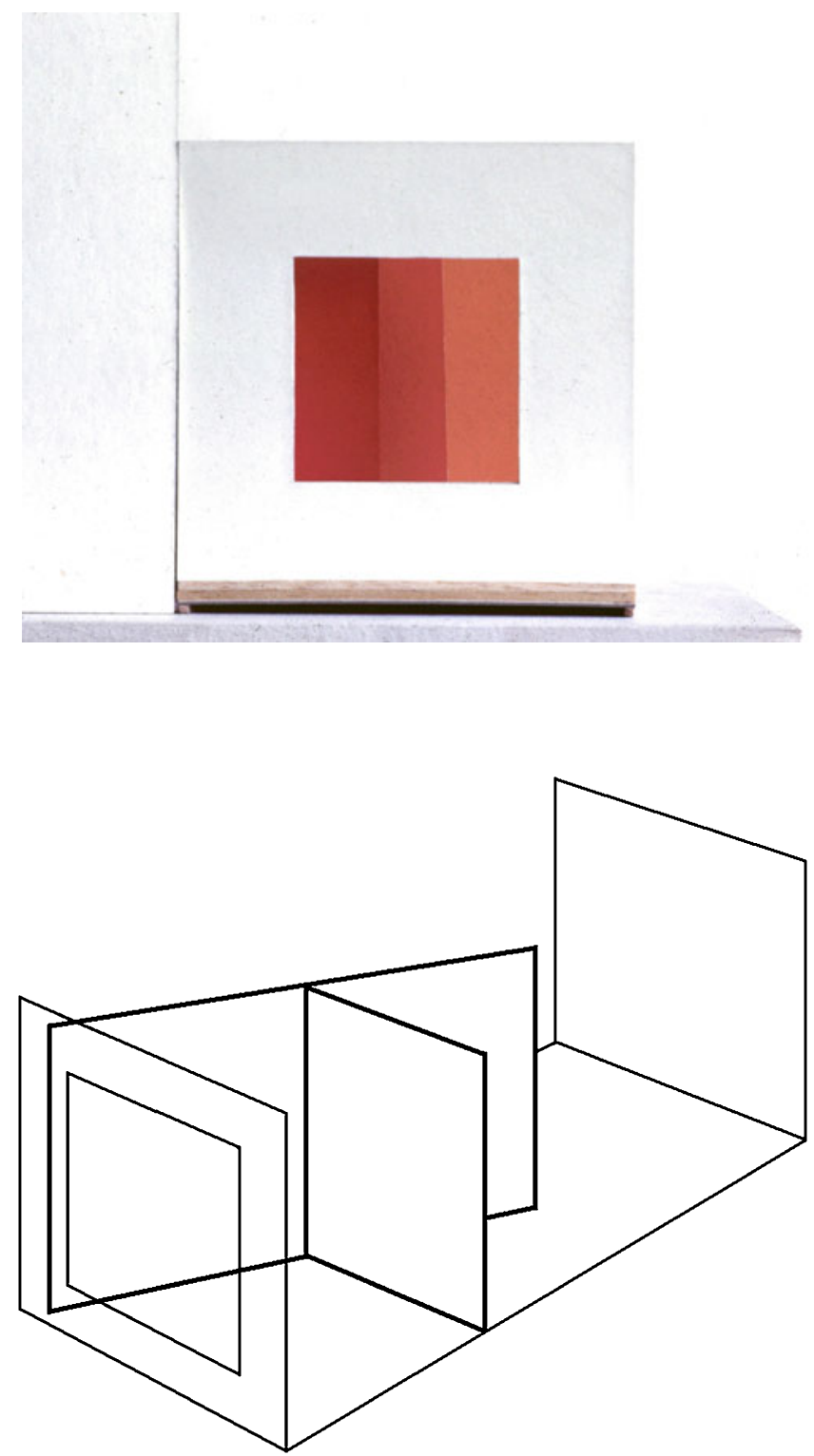

plane to green, followed by a contrast boundary appearing gradually as blue/violet, now adjacent to the red wall, whose contrast boundary appeared yellow - a complete reversal of contrast from the original stimuli of color.

Clearly, the intensity of the colored light provided a much greater stimulus to the visual system than that of a surface color. The color of surfaces induced to change by their adjacency on two-dimensional surfaces contrasts mutually (simultaneous contrast); once perceived, they remain stable. This phenomenon, engendered by the intense light projected in space, seems to have extended to a sequence of perceptual changes which occurred after a much longer time $-8-10 \mathrm{~min}$ of observation. The experience all the observers had was perceptual. The effect eluded all attempts to record it, by film or digitally. To account for these changes, elicited over a period of time, Swirnoff named the effect "sequential contrast." 


\section{Color Contrast,}

Fig. 14 Diagram:

alternative appearance as

zig/zag

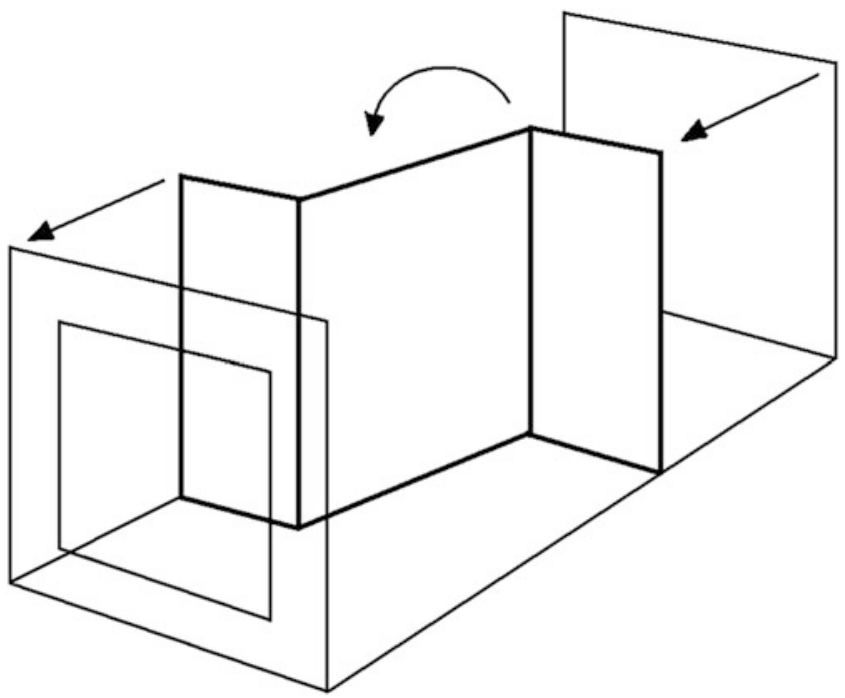

\section{Color Contrast,}

Fig. 15 Pyramids: left, the white model; right, model

flattened by grays

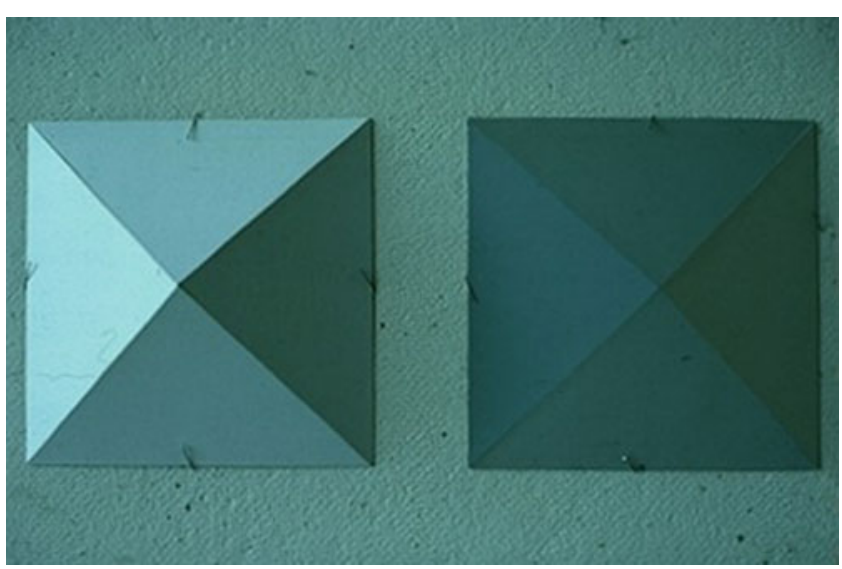

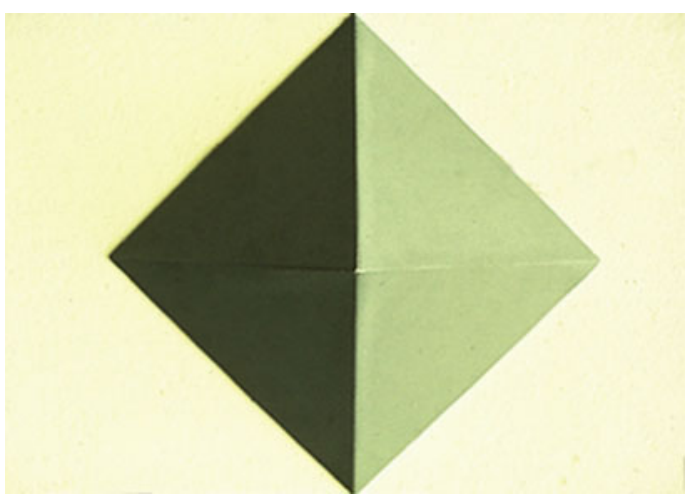

Color Contrast, Fig. 16 Pyramid rotated $90^{\circ}$ appears bisected

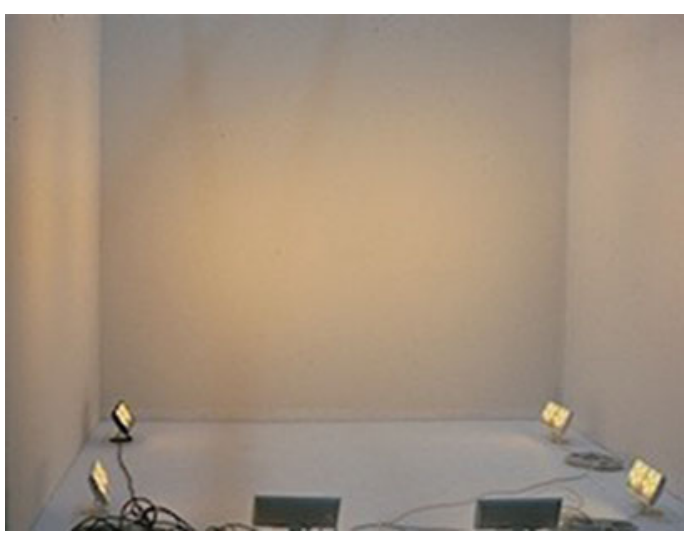

Color Contrast, Fig. 17 The room illuminated by LED 


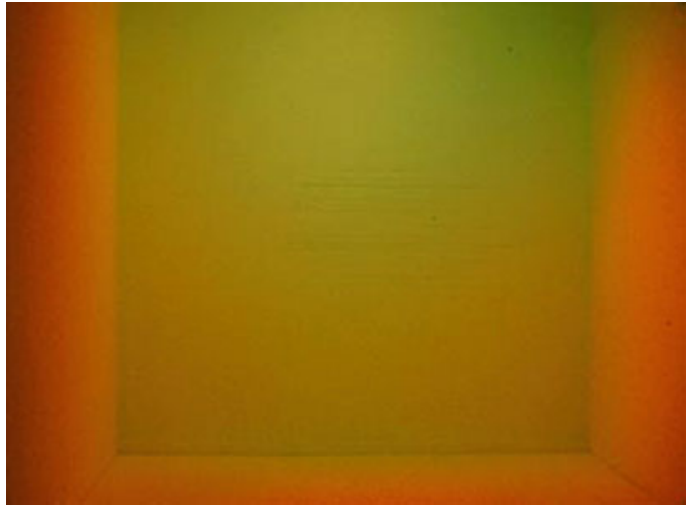

Color Contrast, Fig. 18 The room's back wall changing to green

To conclude, the evidence raised by these experiments suggests that the issue of color contrast is fundamental to and an essential part of the process of sight. Far beyond the purview of design science to explain, however, they offer a challenge now to neurology and brain science.

\section{Effects in Perception}

Contrast detection is the basic visual task from which all other visual behaviors are derived. The human visual system gives virtually no useful information unless there is a contrast in the retina (thus, also in the environment that is being viewed). A small object, or a patch, can only be seen on a larger one if the two differ in color. These differences are known as contrast [7].

Sensation of color, or interpretation of color in the brain, is not only effected by adjacent areas of the stimulus, but also by the light under which the stimulus is seen. Two examples of this are the Helson-Judd effect and the Bezold-Brücke hue shift. The Helson-Judd effect is the tendency of lighter achromatic surfaces to take on the hue of the illuminant under which they are viewed and darker achromatic surfaces to take on the complementary hue. The Bezold-Brücke hue shift is a shift in the apparent color of a stimulus toward yellow or blue with the increasing intensity of light. If a pair of long-wavelength lights differing only in intensity is compared, the higher intensity stimulus will look more yellow and less red than the lower intensity light. For shorter wavelengths, higher intensity lights look more blue and less green than lower intensity lights [7].

Contrast perception also causes visual effects that lead to variance in color sensation. This may be caused by either the psychophysics of the eye or by the interpretation of the brain. These effects are: successive contrast, simultaneous contrast, edge contrast, and assimilation (reversed contrast).

Successive contrast is the visual effect which occurs when eyes are fixed on a colored patch for a sufficient period of time and then moved on to another patch of a different color. It is likely that the image of the first patch will be perceived upon the image of the second with its afterimage [7]. An afterimage is the visual effect that occurs after light stimulus has been removed. In the case of successive contrast, afterimage complementary color of the initially viewed image will be imposed on the lately viewed image.

Simultaneous contrast is the visual effect which occurs when two different color patches are viewed together, where both will exhibit changes of appearance. Simultaneous contrast is affected by the distance between two colors. If two different color patches of equal size are placed side by side, both will exhibit changes in color appearance. When the patches are separated, the changes decrease and eventually diminish, as the distance between them is increased. Simultaneous contrast effects the hue changes by roughly superimposing the complementary color of the background on the foreground patch. This hue change is accompanied by changes in the perceived saturation depending on the afterimage complementary color produced. For example, if a blue-green patch is viewed against a red background, the patch will be perceived as blue-green again (the afterimage of red being a blue-green), but with an increased saturation [8].

If two areas of uniform colors having the same hue but slightly different luminance factor are viewed, adjacent to the boundary between the two areas, there is a relative enhancement of lightness of the lighter area and a corresponding darkening of the adjoining area [8]. This is called edge 
contrast. If a black line is drawn along the edge at which two areas join, the effect of edge contrast is lost. The edge contrast phenomenon is caused psychophysically by interactions among nerve cells in the retina. It is also referred to as the Mach-band effect, the Mach contrast (named after the physicist Ernst Mach), or the border contrast [7].

Assimilation (reversed contrast) is the visual effect which occurs when two distinctly perceived colors seem to shift in appearance toward each other. An example would be strips of colors, namely, red, yellow, and blue. The red strips on the yellow background appear yellowish, and on the blue background, the same red strips appear bluish. Assimilation is also known as the Bezold spreading effect. Assimilation should not be confused with simultaneous contrast. In simultaneous contrast, a red area surrounded by a yellow area would tend to look more bluish (not yellowish); surrounded by a blue area, it would tend to look more yellowish (not bluish) [8]. It is also important to introduce a relation between the viewing distance and the effect that will be perceived. As the viewing distance is increased, producing retinal images of finer detail would be more possible, and a transition from simultaneous contrast to assimilation will occur. Finally, when a distance is reached beyond which the pattern is distinguishable, the visual experience of pointillism takes over where colors put on a surface will be perceived as a spatial mixture (optical mixture) [7].

\section{Sonia Delaunay's Simultaneous Contrast}

This concluding section focuses on Sonia Delaunay's and the early modernism's application of simultaneous contrast. For Sonia, and also for Robert Delaunay, and the poets Apollinaire and Cendrars, simultaneous contrast was a tool used to express the new era's speed, velocity, and movement. In Paris, the Russian-French artist Sonia Delaunay (1885-1979) worked with strong contrasts of color in her early expressionist painting period around 1906. A few years later, she started to work with simultaneous contrast in a non-figurative way in several projects: paintings, fashion, ballet costumes, textiles, prints, books, and interior designs. As early as 1912, she created one of the first painting techniques in an abstract form with colors applied to large areas with the aim of achieving an interaction of color contrast [9]. She picked up the concept of simultaneous contrast from Chevreul and called her style of painting simultanée. Principally, she worked with color contrast to add power and chromatic strength to the tints.

Sonia - and her husband, the painter Robert Delaunay - first observed Chevreul's law in nature. In Spain and Portugal, she writes: the diffusion of light is the purest. The light is so strong that the colors themselves become distinct and their hues become robust. No haze or tones of gray interfere and mix the colors; no achromatic grayed effects appear. The quality of this light allowed the artists "to go even further than Chevreul in finding dissonances in colored light" [10]. She explains "dissonances" as "rapid vibrations, which provoked greater color exaltation by the juxtaposition of specific hot and cold colors" [10]. To create the color vibrations, the Delaunays began to divide the shades of colors into hot and cold. This meant working with complementary colors and, to an even greater degree, with cold and warm color contrasts. Sonia Delaunay states that colors "agitated by hot and cold dissonances provoke a stimulating response" to the viewer [10].

\section{Simultaneous Contrasts in Patterns}

Sonia Delaunay's patterns in pure colors and in new color relationships are varied and have abstract forms: arcs and circles, rectangles, and triangles. For her, the circle was a symbol of the sun and also of simultaneous action. Her patterns change in rhythmic movements corresponding to their movements in value (lightness) and hue. Dresses and costumes are also inspired by the natural movement of the body. She began from the four basic colors - red, yellow, green, and blue - and from black and white. The red hue is often mixed with yellow to form an orange-red. 
The green is mixed with yellow to form a hue similar to the color of a mimosa flower. The blue is a medium blue, and the yellow is strong. In addition, she uses gray [11].

Around 1912, standard fabrics usually had large flowers against black or strongly colored backgrounds [9]. Sonia Delaunay's simultaneous fabrics changed this custom; she manufactured the same elements as those used in her paintings. Her abstract patterns are simple and have clear motifs in composition and color (quite similar to some African patterns). The colors are often vivid, but they harmonize most agreeably. Characteristic of her textile design is that the forms and patterns may well appear geometric, but the color surfaces are "characterized by rhythm" [10]. Due to Sonia Delaunay's simultaneous placement of the colors, they produce new and original effects "right before your eyes" [10]. They are thus responsive to the architecture of modern life, to the new active way of living. In connection with this textile creation, she began to work with the first "simultaneous automobile," a Citroën B12 (1925), painted in the colors of the rainbow. In this way, she was at the forefront in the showing of art outside of the salons.

\section{Simultaneous Contrast in Costume and in Fashion}

During the summer of 1913, Sonia Delaunay began to design simultaneous dresses. She made and mounted them in collages made of textile. These dresses caught a new wave in fashion corresponding with the latest popular dances of the time, foxtrot and tango. In her abstract forms of arcs, circles, rectangles, and triangles, she created a movement of color. But the forms and the contrasting colors also enhanced the natural movement of the forms of the body, matching with the rhythms of Latin music. In the dancehall the Bal Bullier in Montparnasse, one could see the action of the dancers united with the action of color and light. Sonia Delaunay was commissioned to design the costume for the ballet Cléopâtre (1918). Working for the theater, she could experiment with successive designs for lengths of fabric: textiles wrapped around the human form, the body set into action in dance, all visual movements of the costume. Cleopatra's costume was built up of discs in pure colors decorated with sequins and pearls. The ballet established Sonia Delaunay's name as an innovator in both costume and fashion [12]. In 1922, a textile manufacturer in Lyon, France, asked her for a set of fabric designs and promptly ordered 50 designs for silk. For the commission, she began to study color relations and introduced abstract geometrical designs in printed silk. The subject of textile studies refined her control of the interaction of colors [11]. A few years later, on Boulevard Malesherbes in Paris 1925, Sonia Delaunay opened her own shop, the Boutique Simultanée. There she offered simultaneous design in the form of coats, dresses, handbags, and even interior furnishings.

\section{Cross-References}

\author{
- Anchoring Theory of Lightness \\ Appearance \\ - Chevreul, Michel-Eugène \\ - Chromostereopsis \\ - Color Harmony \\ - Color Vision, Opponent Theory \\ Fechner, Gustav Theodor \\ - Mach Bands \\ - Optical Art \\ > Unique Hues
}

\section{References}

1. Gibson, J.J.: The Senses Considered as Perceptual Systems. Houghton Mifflin, Boston (1966)

2. Chevreul, M.-E.: The Principles of Harmony and Contrast of Colors (English translation by Faber Birren). Reinhold, New York (1967)

3. Albers, J.: The Interaction of Color. Yale University Press, New Haven (1963)

4. Hurvich, L.M., Jameson, D.: From contrast to assimilation; in art and in the eye. Leonardo 8, 125-131 (1975)

5. Hering, E.: Outlines of a Theory of the Light Sense (Translated by Leo M. Hurvich and Dorothea Jameson). Harvard University Press, Cambridge, MA (1964) 
6. Swirnoff, L.: Dimensional Color. Birkhauser, Boston (1989). Second revised edition: W. W. Norton, New York (2003)

7. Camgöz, N.: Effects of Hue, Saturation, and Brightness on Attention and Preference. Dissertation. Bilkent University, Ankara (2000). Also available by UMI, Bell \& Howell Co., Ann Arbor (2001)

8. Agoston, G.A.: Color Theory and Its Application in Art and Design. Springer, Berlin (1987)

9. Damase, J.: Sonia Delaunay. Fashion and Fabrics. Thames and Hudson, London (1991)

10. Delaunay, R., Delaunay, S.: The New Art of Color. The Writings of Robert and Sonia Delaunay. The Viking Press, New York (1978)

11. Olsson, G.: The Visible and the Invisible: Color Contrast Phenomena in Space. Axl Books, Stockholm (2009)

12. Delaunay, S.: A Retrospective. Albright-Knox Art Gallery, New York (1980)

\section{Color Coordination}

- Color Combination

\section{Color Dictionaries and Corpora}

Angela M. Brown

College of Optometry, Department of Optometry, Ohio State University, Columbus, OH, USA

\section{Definition}

In the study of linguistics, a corpus is a data set of naturally occurring language (speech or writing) that can be used to generate or test linguistic hypotheses. The study of color naming worldwide has been carried out using three types of data sets: (1) corpora of empirical colornaming data collected from native speakers of many languages; (2) scholarly data sets where the color terms are obtained from dictionaries, wordlists, and other secondary sources; and (3) philological data sets based on analysis of ancient texts.

\section{History of Color Name Corpora and Scholarly Data Sets}

In the middle of the nineteenth century, colorname data sets were primarily from philological analyses of ancient texts [1,2]. Analyses of living languages soon followed, based on the reports of European missionaries and colonialists [3, 4]. In the twentieth century, influential data sets were elicited directly from native speakers [5], finally culminating in full-fledged empirical corpora of color terms elicited using physical color samples, reported by Paul Kay and his collaborators $[6,7]$. Subsequently, scholarly data sets were published based on analyses of secondary sources $[8,9]$. These data sets have been used to test specific hypotheses about the causes of variation in color naming across languages.

From the study of corpora and scholarly data sets, it has been known for over 150 years that languages differ in the number of color terms in common use. Particularly, languages differ greatly in how they name the cool colors that are called "blue" and "green" in English (Fig. 1). Some languages, such as English, use a word $B L U E$ that means only blue, in conjunction with a word GREEN that means only green. Other languages use a single term (here and elsewhere, "GRUE") that means green or blue, and still other languages use a word (here, "BLACK") that means both black and blue, to name the cool colors, in conjunction with WHITE, which names the light and warm colors.

Scholars in the nineteenth century established the two general explanations for this diversity of color terms across languages, which still guide much of the research on the topic today. The first explanation was that the people who spoke languages with few color terms had deficient color vision. This speculation was at first based on the philological analysis of extinct languages and arose in part because of general interest in the theory of evolution in the latter half of the nineteenth century. Proponents of this view speculated that humans and their color vision had evolved since ancient times. The second explanation was that people living at different times and in different cultures need to differentiate between different 